\title{
Subclavius Posticus Muscle with Anomalous Posterior Insertion: Case Report
}

\author{
Músculo Subclavius Posticus con Inserción Posterior Anómala: Reporte de un Caso
}

Moyano, Pablo Joaquín'; Capurro, Martina²; Apa, Sebastián Nicolás ${ }^{3}$ \& Albanese, Eduardo Francisco ${ }^{4}$

MOYANO, P. J.; CAPURRO, M.; APA, S. N. \& ALBANESE, E. F. Subclavius posticus muscle with anomalous posterior insertion: Case report. Int. J. Morphol., 36(1):22-25, 2018.

SUMMARY: During routine anatomical dissection of the left supraclavicular and infraclavicular regions of a male cadaver, a supernumerary muscle was observed, which, by its position and insertions, consistent with the subclavius posticus muscle (posterior subclavius muscle). It had its anterior insertion by a thin tendon in the cranial surface of the first costal cartilage next to the subclavius muscle's insertion, and ran dorso-laterally crossing over the brachial plexus and subclavian vessels to end on the posterior surface of the serratus anterior muscle's fascia near to the superior margin of the scapula, without taking insertion on it, which differentiates it from the muscles described in the bibliography. This aberrant muscle has clinical implication since it has been described as a cause of thoracic outlet syndrome and it may appear in diagnostic imaging techniques simulating different pathological processes.

KEY WORDS: Subclavius posticus muscle; Thoracic outlet syndrome; Anatomic variation; Aberrant muscle; Subclavius muscle; Suprascapular region.

\section{INTRODUCTION}

Subclavius posticus is a rare anatomic variation of the subclavius muscle, which is almost invariably inserted on the first costal cartilage and runs dorsally and posteriorly over the cords of the brachial plexus and subclavian vessels. According to several authors, it is one of the causes of thoracic outlet syndrome and it is consider to be implicated in the Paget-Von-Schrotter syndrome pathogenesis. The majority of the articles describe its posterior insertion on the superior margin of the scapula, near the insertion of the omohyoid muscle. We present an anomalous posterior insertion, since it does not present bone insertion in the superior margin of the scapula; on the contrary, it is going to the posterior surface of the serratus anterior muscle's aponeurosis, ventral to the subscapular muscle.

\section{CASE REPORT}

During routine anatomical dissection of the supraclavicular and infraclavicular regions on the left side of an adult male cadaver at Department of Anatomy, Medical College, Universidad del Salvador, Buenos Aires, Argentina, we observed a supernumerary muscle that was attached, anteriorly, to the first costal cartilage and ran posteriorly and laterally crossing over the brachial plexus and subclavian vessels to end inserted on the fascia of the posterior surface of the serratus anterior muscle between its first two digitations, about $15 \mathrm{~mm}$ medially to the suprascapular notch (coracoid notch). The anterior insertion took place by a thin tendon on the cranial surface of the first costal cartilage, 49 $\mathrm{mm}$ laterally to the sternal portion of the left clavicle, close to the insertion of the subclavius muscle (Figs. 1 and 2).

The muscle found was a thin and flat fascicle composed by a $26 \mathrm{~mm}$ long and $1 \mathrm{~mm}$ wide tendinous portion, and a posterior muscular portion of $75 \mathrm{~mm}$ long and $7 \mathrm{~mm}$ wide at the widest point at the posterior insertion. This structure was located superficially to the subclavian artery and veins and to the cords of the brachial plexus and its branches (Fig. 3). Its posterior insertion arose underneath the omohyoid muscle, separated by the cervical fascia that encloses this muscle.

\footnotetext{
${ }^{1}$ Teaching Assistant - Department of Anatomy. Medical College. Universidad del Salvador, Buenos Aires, Argentina.

${ }^{2}$ Teaching Assistant - Department of Anatomy. Medical College. Universidad del Salvador, Buenos Aires, Argentina.

${ }^{3}$ Plastic Surgeon. Assistant Professor. Department of Anatomy. Medical College. Universidad del Salvador, Buenos Aires, Argentina.

${ }^{4}$ Emeritus Professor. Department of Anatomy. Medical College. Universidad del Salvador, Buenos Aires, Argentina.
} 


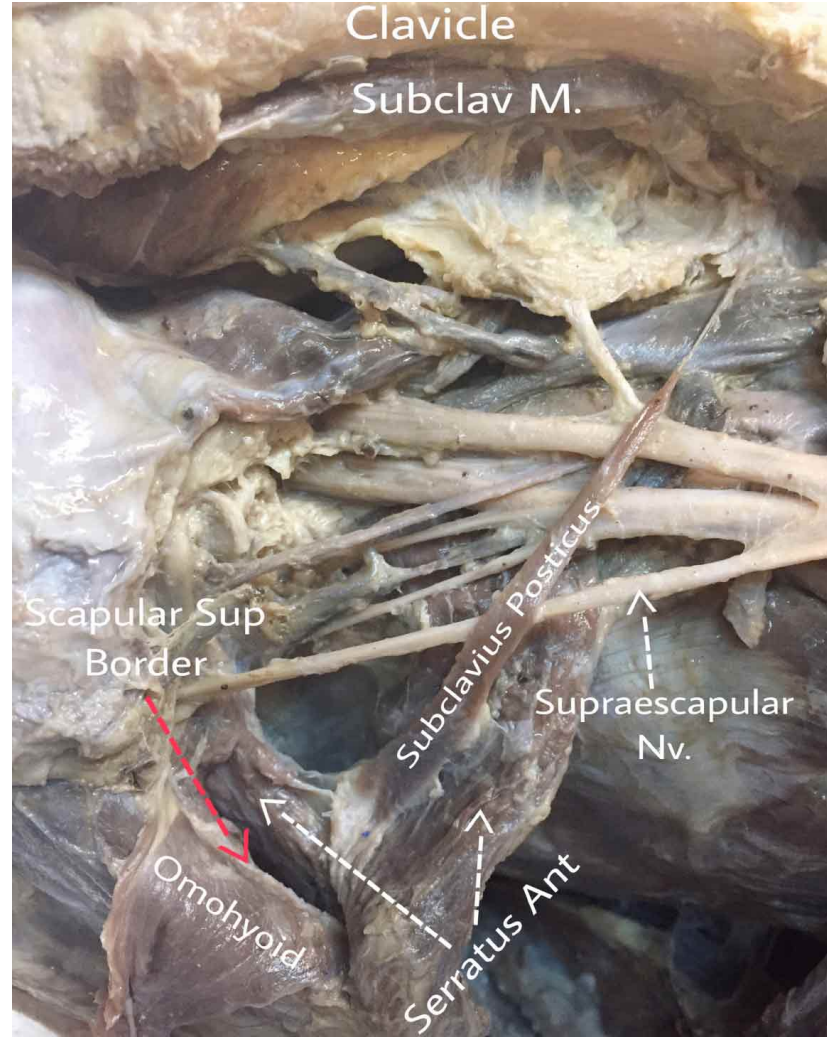

Fig. 1. Superior view of the left infraclavicular region. Omohyoid muscle has been folded back to allow a better view of the relation between subclavius posticus muscle and the superior margin of the scapula. In addition, the subclavius posticus muscle ends on the aponeurosis of the first two digitations of the serratus anterior muscle. Subclav M: Subclavius muscle; Suprascapular Nv: Suprascapular nerve.

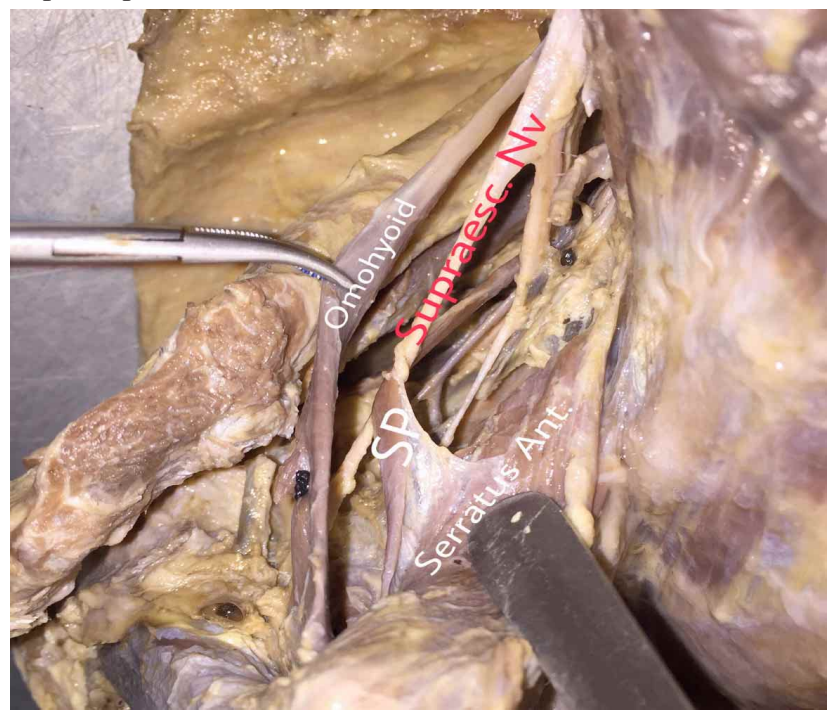

Fig. 2. Internal view of left infraclavicular region. It is shown how the subclavius posticus muscle (S.P.) is intimately attached to the aponeurosis of the serratus anterior muscle. SP: Subclavius posticus muscle; Supraesc Nv: Suprascapular nerve; Serratus Ant: Serratus anterior muscle, first digitation.

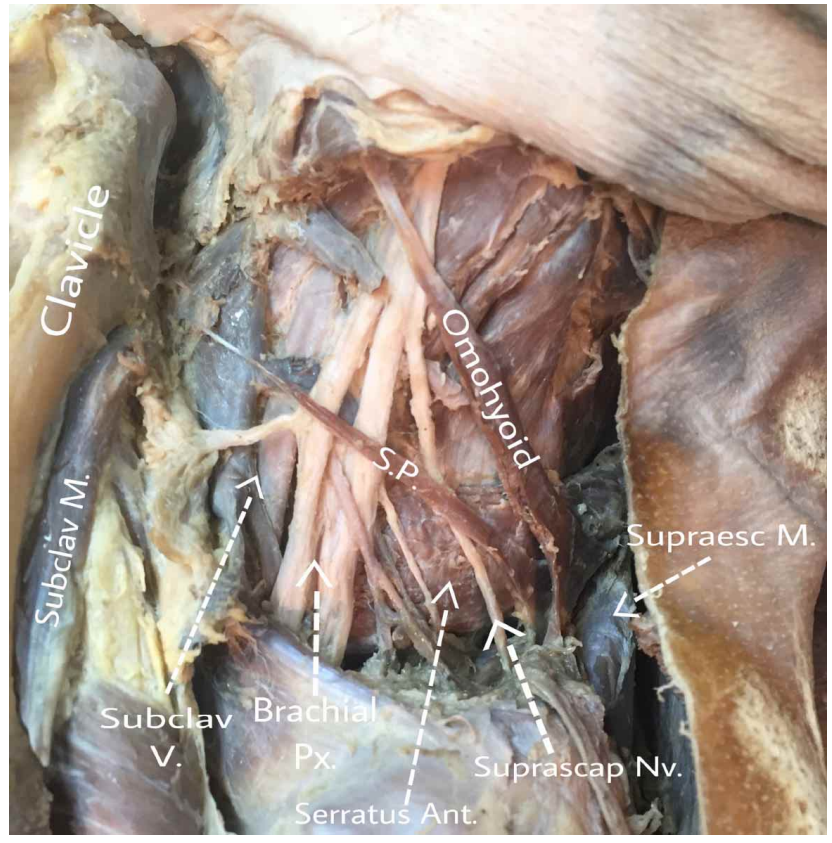

Fig. 3. Lateral and superior view of left infraclavicular region. Clavicle has been removed to improve visualization. The structures related to the subclavius posticus (S.P.) muscle are shown. Supraesc M.: Supraspinatus muscle; Suprascap Nv.: Suprascapular nerve; Brachial Px.: Brachial plexus; Subclav V.: Subclavian vessels; Subclavian M.: Subclavius muscle. Serratus Ant.: First two fascicles of serratus anterior muscle.

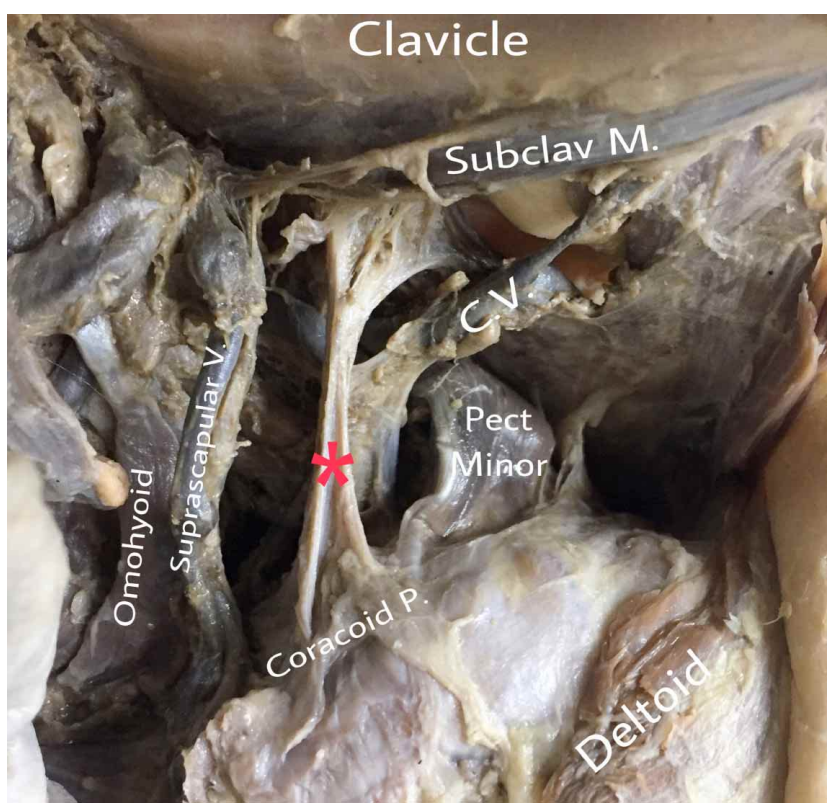

Fig. 4. Superior view of the left infraclavicular region. Clavicle has been rejected anteriorly to improve the view of a fibrous cordon (red asterisk) that goes from the coracoid process (Coracoid P.) to the aponeuroses of the subclavius muscle (Subclav M.) and the pectoralis major muscle. C.V.: Cephalic vein; Pect minor: Pectoralis minor muscle; Suprascapular V.: Suprascapular vein. 
We performed a meticulous dissection on the contralateral side (right side) without finding the same muscle. However, we observed a fibrous structure (Fig. 4) that emerged from the coracoid process and ran anteriorly and medially to attach on the fascia of the subclavius muscle dorsally, and the clavicular insertion of the pectoralis major muscle, ventrally. It measures $50 \mathrm{~mm}$ in its inner inferior part, and $41 \mathrm{~mm}$ in the superoexternal. It passes over the subclavian vein and its branches, being located medial to the drainage of the cephalic vein into the subclavian vein.

\section{DISCUSSION}

Several variations of the subclavius muscle have been described, one of which is the subclavius posticus, first named by Rossenmuller in 1800 and for which Akita et al. (2002), reported an incidence of $8.9 \%$ in 124 dissected Japanese cadavers. Numerous authors have reported its appearance describing its anterior insertion almost invariably, on the cranial surface of the first costal cartilage and its posterior insertion on the superior margin of the scapula, superior transverse ligament of the scapula, base of the coracoid process or capsule of the acromioclavicular joint. It has been described as innervated by the subclavian nerve (Akita $e t$ al., 1996; Shetty et al., 2006; Martin et al., 2008), as by the suprascapular nerve (Forcada et al., 2001; Sarikcioglu \& Sindel, 2001; Singhal et al., 2008). Akita et al. (1996) based on its innervation, described the muscle as a variation of the subclavian muscle rather than the omohyoid.

Testut \& Latarjet (1951) has indicated that in case of absence of the subclavian muscle, the most common approach is to find a more developed muscle, the sternochondroscapularis, which goes from the first rib, or from the sternum, to the superior margin of the scapula.

Wood (1870) described some muscles with these features, including one with posterior insertions at the level of the superior transverse ligament of the scapula [coracoid ligament] and on the base of the coracoid process where it was connected to the omohyoid muscle origin. The anterior insertion took place on the first costal cartilage, close to the sternum. Wagner also found a muscle that originated posteriorly with the omohyoid muscle inserted into the suprascapular notch, and he considered it as an anatomical variation of the omohyoid muscle (Wood).

Hallett, Gruber, Lushka, Henle and other authors also considered muscles with similar characteristics to those described by the authors cited previously (Wood) to be variations of the omohyoid muscle, whereas Theile, considered a muscle that ran from the first costal cartilage to the base of the coracoid process in a male corpse as a variation of the serratus anterior muscle (Wood).

Singhal et al. performed a review regarding the characteristics of this muscle according to different authors, in which it appears that the posterior insertion always takes place on a bone surface or ligament, reaching the superior margin of the scapula. Shetty et al. describe a posterior insertion on a ligament that extends from the medial margin of the suprascapular notch to the acromioclavicular joint's capsule, on the right side of the infraclavicular region of a male cadaver.

Other authors such as Akita et al. (1996, 2002), Forcada et al. and Martin et al., also described the posterior insertion at the scapula's superior margin, and adding to the description, the last two authors also report it inserted into the scapula's superior transverse ligament and on the base of the coracoid process.

This anomaly has true clinical implication since several authors described the subclavius posticus muscle as a cause of thoracic outlet syndrome by compressing the structures of the cervicoaxillary region with which it is closely related (Akita et al., 2002; Forcada et al.). Muellner et al. (2015) and Ozçakar et al. (2010) reported cases in young patients who presented with pain and weakness in the upper limb. Muellner et al., in addition, described the presence of macrodactyly in the middle finger of the same limb in that patient. Cogar et al. (2015) described in a 49year-old male athlete, compression of the suprascapular nerve by the subclavius posticus muscle, whose symptoms improved rapidly after surgical excision.

Kolpattil et al. (2009) reported a case in which the subclavius posticus muscle appeared as a mammographic density, and could be confused with a pathological mammary process.

Akita et al. (2000), also proposed it as a cause of the Paget-von Schrotter syndrome, which consists of the subclavian or axillary vein thrombosis, either spontaneous or effort-related.

Our case describes a muscle that is inserted anteriorly, as the cases described by the aforementioned authors, on the first costal cartilage, but we found a difference concerning the posterior insertion, since it does not present any bone insertion, and, on the contrary, it ends on the serratus anterior muscle's fascia, close to the superior margin of the scapula. After extensive bibliographical search we found that cases with such posterior insertion have not been described yet. 


\section{CONCLUSION}

There are several reports regarding variations of the subclavius muscle with the previously described characteristics, and many present very similar insertions, especially the anterior insertion on the first costal cartilage, which happens almost invariably. However, the posterior portion presents a wide range of possible insertions, mostly on bone or ligaments. We present a posterior insertion that is not described in the bibliography.

MOYANO, P. J.; CAPURRO, M.; APA, S. N. \& ALBANESE, E. F. Músculo subclavius posticus con inserción posterior anómala. Reporte de un caso. Int. J. Morphol., 36(1):22-25, 2018.

RESUMEN: Durante una disección de rutina de las regiones supraclavicular e infraclavicular izquierdas de un cadáver masculino, observamos un músculo supernumerario, el cual según su ubicación, origen e inserción, se corresponde con la descripción del músculo subclavius posticus (subclavio posterior). Presenta su inserción anterior mediante un delgado tendón en la cara superior del primer cartílago costal, a un lado de la inserción del músculo subclavio, y corre hacia posterior y lateral, cruzando por encima de los troncos del plexo braquial y los vasos subclavios para terminar en la superficie posterior de la fascia del músculo serrato anterior, cerca del margen superior de la escápula, sin prestar inserción en él, lo cual lo diferencia de los músculos descritos en la bibliografía. Este músculo tiene implicancia clínica debido a que ha sido descrito como causa del síndrome del estrecho superior torácico, y puede aparecer simulando procesos patológicos en estudios por imágenes.

PALABRAS CLAVE: Músculo subclavius posticus; Síndrome del estrecho superior torácico; Variación anatómica; Músculo aberrante; Músculo subclavio; Región supraescapular.

\section{REFERENCES}

Akita, K.; Ibukuro, K.; Yamaguchi, K.; Heima, S. \& Sato, T. The subclavius posticus muscle: a factor in arterial, venous or brachial plexus compression? Surg. Radiol. Anat., 22(2):111-5, 2002.

Akita, K.; Tsuboi, Y.; Sakamoto, H. \& Sato, T. A case of muscle subclavius posticus with special reference to its innervation. Surg. Radiol. Anat., 18(4):335-7, 1996.

Cogar, A. C.; Johnsen, P. H.; Potter, H. G. \& Wolfe, S. W. Subclavius posticus: an anomalous muscle in association with suprascapular nerve compression in an athlete. Hand (N. Y.), 10(1):76-9, 2015.

Forcada, P.; Rodríguez-Niedenführ, M.; Llusá, M. \& Carrera, A. Subclavius posticus muscle: supernumerary muscle as a potential cause for thoracic outlet syndrome. Clin. Anat., 14(1):55-7, 2001.

Kolpattil, S.; Harland, R. \& Temperley, D. Case report: a case of subclavius posticus muscle mimicking a mass on mammogram.Clin. Radiol., 64(7):738-40, 2009.
Martin, R. M.; Vyas, N. M.; Sedlmayr, J. C. \& Wisco, J. J. Bilateral variation of subclavius muscle resembling subclavius posticus. Surg. Radiol. Anat., 30(2):171-4, 2008.

Muellner, J.; Kaelin-Lang, A.; Pfeiffer, O. \& El-Koussy, M. M. Neurogenic thoracic outlet syndrome due to subclavius posticus muscle with dynamic brachial plexus compression: a case report. B. M. C. Res. Notes, $8: 351,2015$

Ozçakar, L.; Güney, M. S.; Ozdag, F.; Alay, S.; Kiralp, M. Z.; Görür, R. \& Saraçoglu, M. A sledgehammer on the brachial plexus: thoracic outlet syndrome, subclavius posticus muscle, and traction in aggregate. Arch. Phys. Med. Rehabil., 91(4):656-8, 2010.

Sarikcioglu, L. \& Sindel, M. A case with subclavius posticus muscle. Folia. Morphol. (Warsz.), 60(3):229-31, 2001.

Shetty, P.; Pai, M. M.; Prabhu, L. V.; Vadgaonkar, R.; Nayak, S. R. \& Shivanandan. The subclavius posticus muscle: Its phylogenetic retention and clinical relevance. Int. J. Morphol., 24(4):599-600, 2006.

Singhal, S.; Vijaya Rao, V. \& Manjunath, K. Y. Subclavius posticus muscle: A case report. Int. J. Morphol., 26(4):813-5, 2008.

Testut, L. \& Latarjet, A. Tratado de Anatomía Humana. $9^{\mathrm{a}}$ ed. Barcelona, Salvat, 1951.

Wood, J. On a group of varieties of the muscles of the human neck, shoulder, and chest, with their transitional forms and homologies in the mammalia. Phil. Trans. R. Soc., 160:83-116, 1870

Corresponding author:

Moyano, Pablo Joaquín

Universidad del Salvador

Facultad de Medicina

Cátedra de Anatomía

Hospital Italiano de Buenos Aires

Servicio de Anestesiologia

Buenos Aires

ARGENTINA

E-mail: pablo.moyano@hospitalitaliano.org.ar

Received: 31-05-2017

Accepted: 28-08-2017 